IRA-International Journal of Management \& Social Sciences

ISSN 2455-2267; Vol.04, Issue 03 (2016)

Pg. no. 556-561

Institute of Research Advances

http://research-advances.org/index.php/RAJMSS

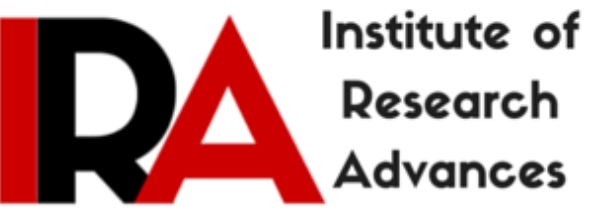

\title{
Mobile Phone Handsets Industry Greatly Influence the Teenagers: The Positive Aspects
}

\author{
${ }^{1}$ Prof. Satish Agarwal \\ Professor, Maharishi Dayanand \\ Saraswati University, Ajmer, India. \\ ${ }^{2}$ Priyanka Bhagoliwal \\ Research Scholar, Maharishi Dayanand Saraswati \\ University, Ajmer, India.
}

Type of Review: Peer Reviewed.

DOI: http://dx.doi.org/10.21013/jmss.v4.n3.p5

\section{How to cite this paper:}

Agarwal, S., \& Bhagoliwal, P. (2016). Mobile Phone Handsets Industry Greatly Influence the Teenagers: The Positive Aspects. IRA-International Journal of Management \& Social Sciences (ISSN 2455-2267), 4(3), 556-561. doi:http://dx.doi.org/10.21013/jmss.v4.n3.p5

(C) Institute of Research Advances

\section{(cc) BY-NC}

This work is licensed under a Creative Commons Attribution-Non Commercial 4.0 International License subject to proper citation to the publication source of the work.

Disclaimer: The scholarly papers as reviewed and published by the Institute of Research Advances (IRA) are the views and opinions of their respective authors and are not the views or opinions of the IRA. The IRA disclaims of any harm or loss caused due to the published content to any party. 


\section{ABSTRACT}

The mobile phone handset industry is growing at a fast pace in the world and is dominating the Indian market with Hi-Tech products and innovation. This industry offers products and services with advanced technology and innovation making it an important gadget for survival among the people. It is hard to imagine a life without mobile phones. The study describes the various features of mobile phone handsets which are valued by the teenagers so as to place and promote the products perfectly. The study found that teenagers frequently use mobile phones mainly for games, social networking, chatting on Whatsapp, listening to music, browsing the internet, and feels that mobile phone handset is a style statement and it exhibits their status, standard, esteem etc.

\section{Keywords}

Mobile phones, Teenagers, Lifestyle, Purpose of use, Advantages

\section{Introduction}

Mobile phones, nowadays "Smartphones", have become one of the people's best companions of all time. Almost everyone owns a mobile phone. It has become a survival need. The mobile phone handset companies have targeted each and every segment of the market with differentiated product features, designs and colors. The market is flodded with umpteen smartphones ranging from very low price of 1500 Rs (Micromax X853) to high price of 99,000 Rs (Motorola Moto Razr2). Earlier mobile phones were used only for making calls. Then some more features were added to the product like bluetooth, FM, camera, media player, games etc. The competition in the market took a hike and mobile phone handset companies came up with a more upgraded version of mobile phones having touch screens, high pixcel camera, front camera, long lasting batteries etc. Technological upgradation continues and mobile phone handset industry reached a stage of hyper competition in the market. Innovation is the key to success indeed. The advancement in technology and innovation has revolutionalised the day to day life of society. The introduction of high speed internet, mobile applications such as WhatsApp, Game zone, UC Browser, Saavn, DU Speed booster, Facebook, Twitter, Gmail, etc. lead to transformation of mobile phones usage. These mobile applications appealed the teenagers the most. Teenagers considered smartphones as fashion statement. Most of them owns a mobile phone to play games, listening to music, chatting, internet browsing etc. It consumes a lot of energy as well as time which they can utilize in some other important work. They are less likely to do their academic work through smartphones. Teenagers attachement to smartphones has been one of the major issues of concern for the parents. It changes their lifestyle, values, and personality. They can ignore the whole world if they are playing some game or chatting with their friends on phone. It adversely affect their day to day life and it may even hamper their growth. However, teenagers does not feels the same. For them there are many advantages of having a mobile phone. They feel it is very important to own a mobile phone and tht there is no harm in the same. This paper aims at identifying the various mobile phone usage by teenagers and there views regarding the effects of mobile phone on their lifestyle, education and overal growth.

\section{Review of literature}

"Mobile phones are not just a tool for communication, as per the new generation, rather it's a way to express their feelings and emotions" (Ito and Okabe, 2004). "Also it's a gadget which makes them look cool". (Ling, 2001). "The young generation these days is techno savy, as they are born in technological era and so they are more attracted towards technological gadgets". (Abdullah,2004).

"Most of the youngsters these days suffer from a mental desease called "mobile phone dependence syndrome'. Such people are often isolated from the society and suffer economic lossess". (Ishfaq Ahmed, Tehmina Fiaz Qazi and Khadija Aijaz Perji). "The lack of control and improper usage of mobile phone 
handsets gives rise to social and behavioral issues. These also leads to affective problems. The teenagers posses mobile phones as it fulfills their esteem needs and provide identity in comparison with their peers". (Lobet-Maris C). "The Prime Minister of Japan commented that "I can't think of one good reason of letting youngsters to have a mobile phone. Mobile phones are hrmful for children as it affects their social relations as well as their education". In Japan, mobile phones are used by teenagers as it provides a sense of freedom from their family". (Ishii). Past researches shows that mobile phone handset may cause serious harm to the users health and well being. "The excessive use of mobile phone handset may cause psychological disorders to the users", (Jee Hyun Ha, Bumsu Chin, Doo-Heum Park, Seung-Ho Ryu, Jaehak Yu). One such study conducted with a sample size of 595 Korean students revealed that "the students who are preoccupied with mobile phones suffer from serious deseases like depression, higher interpersonal anxiety, lower self esteem etc'.(Jee Hyun et al, 2008). The addictive behaviour of mobile phone users specially students highly influence their sleeping patterns as they text messages and then become anxious when they do not receive replies from their friends. They keep on checking their mobile phone even during night. (Van Den Bulk).

The after effects of high mobile phone exposure are stress, disturbance in sleep, mental overload, feeling of never being free, anxiety, dependency, and guilt of not returning to all calls and messages. (Thomee $S$, Dellve L, Harenstam A, Hagberg M). There are similar studies which shows other symptoms of high utilisation of mobile phone handsets by the youngsters. Mobile phones have been associated with severe problems like "insomania, anxiety (Jenaro C, Flores N, Gómez-Vela M, González-Gil F, Caballo C), feeling low or depressed (Yen CF, Tang TC, Yen JY, Lin HC, Huang CF, Liu SC, Ko CH), psychological disorders (Beranuy M, Oberst U, Carbonell X, Chamarro A), unhealthy and disturbed lifestyle". (Ezoe S, Toda M, Yoshimura K, Naritomi A, Den R, Morimoto K).

\section{Research Gap}

The literature available through various sources related to the effects of mobile phone handsets on the teenagers have been studied. It suggests that most of the studies have been done regarding the negative effects of mobile phone on teenagers life and health. There are studies regarding how mobile phones have been sploiting the lifestyles of teenagers and is an obstacle to their growth and development. However, very few studies suggests the advantages of mobile phone handsets. The study describes the various positive aspects of mobile phone handsets usage by the teenagers.

\section{Research methodology}

The research is qualitative in nature as it includes indepth interviews so as to find out the reasons of human behaviour and investigating underlying motives and desires.

\section{Sampling}

Sampling method

- Convenience sampling:- The sampling method opted for the study is convenience sampling, which is a type of non-probability sampling methods. In Convinience sampling, elements are selected because of their availability or easy access and willingness to provide information.

\section{Sampling units}

The sampling units selected for the study are teenagers, both male and female, of age 15 to 19 , who owns a mobile phone handset. 


\section{Sample size}

Sample size for the study is 28 respondents belonging to Jaipur city, of which 17 were boys and 11 girls were interviewd.

\section{Data collection}

\section{Primary sources}

Data collection tool used is standardised open ended interviews, where in the same open-ended questions are asked to all interviewees; this approach facilitates faster interviews that can be more easily analyzed and compared.

Secondary sources

- Books

- Internet

\section{Findings and Analysis}

The mobile phone handset industry is itself evolving and captured the minds of teenagers the most. Almost all the teenagers owns a mobile phone and they do not find any difficulties in operating the handsets and its various applications. They are more techno savy as they understand the technological as well as configurational capabilities of a mobile phone. The respondents when asked about the brand of mobile phone they possess currently, 14 out of 28 i.e 50\% posses Samsung, 8 respondents i.e 28.57\% owns Micromax , 3 respondents i.e 10.71\% possess Apple and 3 respondents i.e $10.71 \%$ possess Lenovo. When they were asked about the next preffered brand 17 respondents i.e $60 \%$ preffered to have Samsung, and 11 respondents i.e $40 \%$ preffered to have Apple iphone.

Another question raised was the use of mobile phone. Most of the respondents use mobile for text messages, whats app, as it is cheapest of all the sources of connectivity and they can chat with friends and family without any limitation of time and place. The study found that majority of the respondents preffer to use SMS then to make calls. Nearly all the respondents stated that they text messages daily.

The second feature popularly used by teenagers is the social networking sites and the most famous amongst all of them is Facebook. All the respondents check their facebook account daily. 22 respondents 1 to 2 hours on facebook and wish Birthdays, good lucks, share photographs, location, status and other such stuff to friends through Facebook.

The teenagers feel that there are'nt any negative effects of owing a mobile phone rather there are many advantages. The children of all age feels that everyone should own a mobile phone as it is a very useful device. The respondents have given many benefits of owing a mobile phone. These are as follows:-

- Almost all the respondents i.e $92.85 \%$ (26 out of the total 28 respondents) stated that the facility of text messages is the biggest advantage of a mobile phone as they can use SMS to chat with their friends, take some information, share some news. They feel it is beneficial for them as it is the cheapest of all other ways of connectivity and hence they can get it recharged easily from their pocket money. As they are financially dependent on their parents, their parents would not stop them from spending such a little amount.

- Another advantage stated by them is easy access to internet. $96.42 \%$ respondents stated that easy accesss to high speed internet is the biggest advantage of mobile phone. For some respondents it helps them in their education as it is the best source of collecting information for doing some 
assignment, reading online dictionary, for others it is good for downloading songs and videos, downloading free applications etc.

- Out of the total respondents , 25 respondents i.e $89.28 \%$ feels that mobile phone allow them to remain connected with their friends and family members through social networking sites. Facebook, Twitter, Whats app and other such social networking sites are on their finger tips furthermore, It improves their social relations without any restrictions of time and space.

- For some playing games is one of the benefits of mobile phone. Out of the total 28 respondents, 22 respondents i.e $78.58 \%$ play games on mobile phone daily. Some have stated that playing games on mobile phone refresh their mind and it is a stress buster while others have said that playing games on mobile phone open up their mind and gives the ability to think of the various alternatives in real life.

- Most girl respondents feels that they feel safe if they have a mobile phone as they can contact their parents as and when they need. Moreover they can call police, ambulance etc in case of an emergency.

- Some respondents knew about the location tracking system. They stated that it is very helpful as there parents can track their location. It gives a sense of safety to the children and to the parents as well.

- They want to take mobile to schools. Out of the total 28 respondents, 15 respondents i.e 53.57\% feels that they should be allowed to take mobile phones to their school, as it will give them a sense of pride and it shows their status. For them, owing a mobile phone is a style statement and they can have a huge friend circle as more and more classmates get attracted towards them.

- Out of the total 28 respondents 21 respondents i.e $75 \%$ feels that owing a mobile phone adds more confidence and spark to their personality.

Hence, mobile phones have become one of the most essential gadget of the daily lives of teenagers. They cannot think of surviving without mobile phone. It has become their friend for life, a personal diary, personal calendar, alarm, personal camera, complete game zone and a very good source of entertainment. The teenagers are eager to find their own identity and to establish, improve and increase their social network and hence mobile phones have been one of the highly accepted gadgets as one of the survival needs. It has become a universal gadget.

\section{Bibliography}

1. Abdullah, M. Y. H. (2004). "Adoption of cellular phone among young adults: A study among youths in the Klang Valley, Malaysia”. Paper presented at the The Mobile Communication and Social Change, edited by S. D. Kim. Seoul: SK Telecom

2. Beranuy M, Oberst U, Carbonell X, Chamarro A: Problematic Internet and mobile phone use and clinical symptoms in college students: The role of emotional intelligence. Computers in Human Behavior 2009, 25(5):1182-1187.

3. Ezoe S, Toda M, Yoshimura K, Naritomi A, Den R, Morimoto K: Relationships of personality and lifestyle with mobile phone dependence among female nursing students. Social Behavior and Personality 2009, 37(2):231-238.

4. Ishfaq Ahmed, Tehmina Fiaz Qazi and Khadija Aijaz Perji, "Mobile phone to youngsters: Necessity or addiction" , African Journal of Business Management Vol.5 (32), pp. 1251212519,14 Dcember, 2011.

5. Ishi Kenichi (2006). "Implications of Mobility: The Uses of Personal Communication Media in Everyday Life". Journal of Communication, 56, 346-365.

6. Ito Mizuko and Okabe Daisuke, (2004). Mobile Phones, Japanese Youth, and the Replacement of Social Contact,www.itofisher.com/mito/archives/mobileyouth.pdf 
7. Jee Hyun Ha, Bumsu Chin, Doo-Heum Park, Seung-Ho Ryu, Jaehak Yu. Characteristics of Excessive Cellular Phone Use in Korean Students. CyberPsychology \& Behavior. December 1, 2008, 11(6): 783-784. doi:10.1089/cpb.2008.0096

8. Jee Hyun Ha, Bumsu Chin, Doo-Heum Park, Seung-Ho Ryu, Jaehak Yu. Characteristics of Excessive Cellular Phone Use in Korean Students. CyberPsychology \& Behavior. December 1, 2008, 11(6): 783-784. doi:10.1089/cpb.2008.0096.

9. Jenaro C, Flores N, Gómez-Vela M, González-Gil F, Caballo C: Problematic internet and cellphone use: Psychological, behavioral, and health correlates. Addiction Research and Theory 2007, 15(3):309-320.

10. Ling, R. (2001). Students girls and young adult men: Two sub-cultures of the mobile telephone, Kjeller. Telenor Research and Development, 2001 (R\&D report r 34/2001).

11. Lobet-Maris C. "Mobile phone tribes: youth and social identity", Mediating the Human Body: Technology, Communication and Fashion. New York, NY: Lawrence Erlbaum; 2003, p. 93-102.

12. Thomee S, Dellve L, Harenstam A, Hagberg M: Perceived connections between information and communication technology use and mental symptoms among young adults - a qualitative study. BMC Public Health 2010, 10(1):66.

13. Van den Bulck, J. (2003). Text messaging as a cause of sleep interruption in adolescents, evidence from a cross-sectional study. Journal of Sleep Research, 12(3).

14. Yen CF, Tang TC, Yen JY, Lin HC, Huang CF, Liu SC, Ko CH: Symptoms of problematic cellular phone use, functional impairment and its association with depression among adolescents in Southern Taiwan. Journal of Adolescence 2009, 32(4):863-873. 